\title{
The Effect of Morphological Characteristic of Coarse Aggregates Measured with Fractal Dimension on Asphalt Mixture's High-Temperature Performance
}

\author{
Hainian Wang, ${ }^{1}$ Yin Bu, ${ }^{1}$ Yanzhe Wang, ${ }^{1} \mathrm{Xu} \mathrm{Yang}^{2}$ and Zhanping $\mathrm{You}^{2}$ \\ ${ }^{1}$ School of Highway, Chang'an University, Xian, Shaanxi 710064, China \\ ${ }^{2}$ Department of Civil and Environmental Engineering, Michigan Technological University, 1400 Townsend Drive, \\ Houghton, MI 49931-1295, USA
}

Correspondence should be addressed to Hainian Wang; wanghnchd@gmail.com

Received 17 November 2015; Accepted 3 February 2016

Academic Editor: Luigi Nicolais

Copyright (C) 2016 Hainian Wang et al. This is an open access article distributed under the Creative Commons Attribution License, which permits unrestricted use, distribution, and reproduction in any medium, provided the original work is properly cited.

\begin{abstract}
The morphological properties of coarse aggregates, such as shape, angularity, and surface texture, have a great influence on the mechanical performance of asphalt mixtures. This study aims to investigate the effect of coarse aggregate morphological properties on the high-temperature performance of asphalt mixtures. A modified Los Angeles (LA) abrasion test was employed to produce aggregates with various morphological properties by applying abrasion cycles of $0,200,400,600,800,1000$, and 1200 on crushed angular aggregates. Based on a laboratory-developed Morphology Analysis System for Coarse Aggregates (MASCA), the morphological properties of the coarse aggregate particles were quantified using the index of fractal dimension. The hightemperature performances of the dense-graded asphalt mixture (AC-16), gap-graded stone asphalt mixture (SAC-16), and stone mastic asphalt (SMA-16) mixtures containing aggregates with different fractal dimensions were evaluated through the dynamic stability (DS) test and the penetration shear test in laboratory. Good linear correlations between the fractal dimension and hightemperature indexes were obtained for all three types of mixtures. Moreover, the results also indicated that higher coarse aggregate angularity leads to stronger high-temperature shear resistance of asphalt mixtures.
\end{abstract}

\section{Introduction}

Asphalt mixture is a multiphase composite material which consists of aggregates with gradation as the rigid solid and asphalt as the binder [1]. The mechanical properties of asphalt mixtures are influenced by the fractions and properties of each phase. Since aggregate occupies the majority of both the volume (over 80\%) and the mass (about 95\%) of the asphalt mixture, the physical and mechanical performances of asphalt mixture are greatly influenced by the geometric morphology of aggregate particles and the mutual interaction among them.

The morphological characteristics of coarse aggregates include shape, angularity, and surface texture. In compacted asphalt mixtures, the spatial distribution and effective contact between stone particles depend on the shape, angularity, and surface texture of aggregate particles, especially for coarse aggregates (Figure 1). Due to the lower modulus of asphalt binder at high temperatures, the high-temperature shear strength of the asphalt mixture is notably contributed to by aggregate interlock, which is mostly influenced by the morphological characteristic of mineral aggregate. Tokyay and Akcaoglu reported that the irregular shape of coarse aggregates may lead to stress concentration in composite material, consequently causing the initiation and propagation of microcracking, which will finally change the macrostructure and microstructure of materials and lead to the degradation of the mixture's overall strength [2]. Thus, the successful quantification of shape, angularity, and surface texture is essential in understanding their effects on pavement performance and selecting aggregates to produce asphalt pavements with adequate quality to meet the increasing traffic volume and loading.

The National Association of Aggregate (NAA) proposed an "uncompacted void content" testing method for aggregates, which is included in the specification by the American 


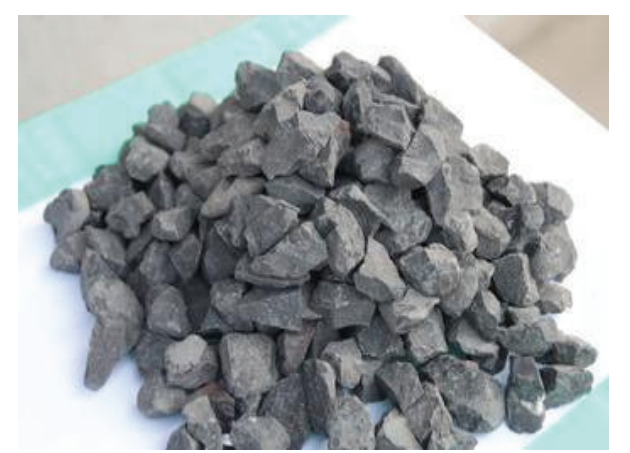

(a)

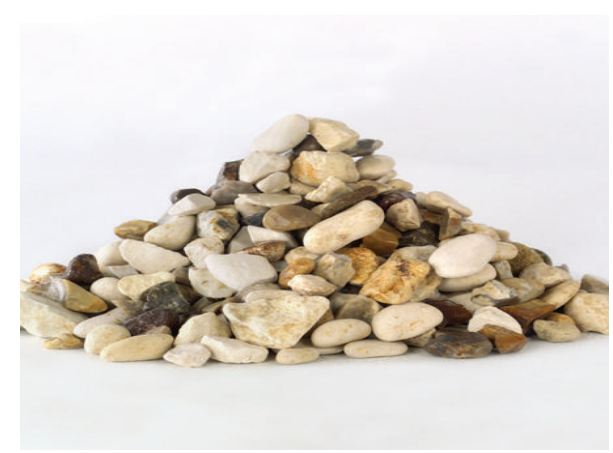

(b)

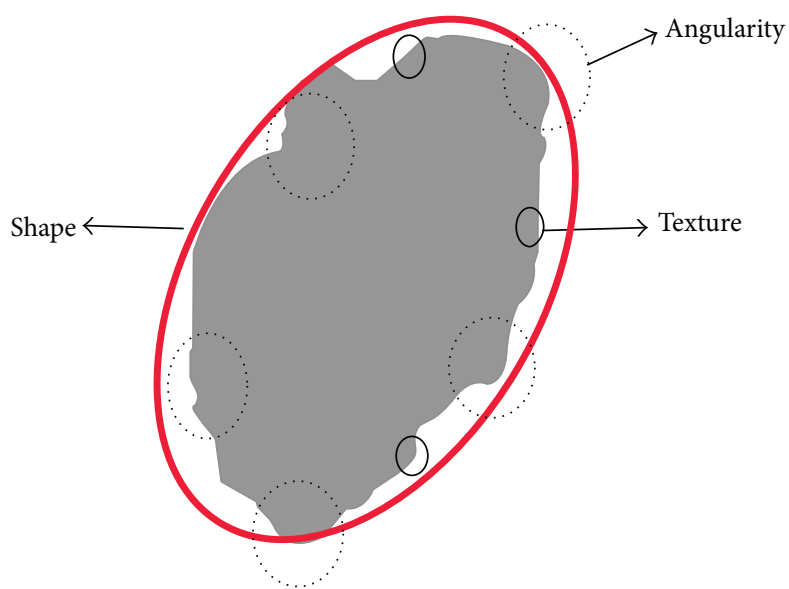

(c)

FIGURE 1: Illustration of morphological characteristic of aggregates: (a) angular aggregates; (b) subround aggregates; (c) shape characterization.

Society for Testing and Materials (ASTM) and the American Association of State Highway and Transportation Officials (AASHTO) [3]. In addition, ASTM put forward the standard "number of fractured faces" testing method (ASTM D5821 2006), the "percentage of flat-elongated particles" testing method (ASTM D4791), and the standard "shape and texture indicators of aggregate particles" testing method (ASTM D3398), and so forth. Some of these methods were adopted by AASHTO [4]. However, the current testing methods are empirical and time-consuming in assessing the angularity of coarse aggregate. The development of computer science has motivated the application of cutting-edge methods such as digital image processing in the engineering field [5]. Various devices and measuring methods were successfully developed for the morphological characteristic of aggregates based on the digital image processing technology, such as the computer programs of Particles Analysis (CPA) [6], Aggregate Image Analyzer (UIAIA) [7], Aggregate Imaging System (AIMS) [8], and Fourier Transform Interferometry (FTI) system [9]. More objective, simple, and credible testing methods were contributed by these research results to quantify the aggregate shape features.

Fractal geometry has been known as a modern mathematical tool to describe the irregular geometric shapes by the French mathematician, Mandelbrot. The degree of irregularity can be measured by fractal dimension by providing a quantitative index to describe the statistical selfsimilarity of complex phenomena [10]. The fractal dimension is a quantitative parameter which can describe the complex graphics of geometric forms and connect the microstructure and the macroperformance of a compound material [11]. Therefore, the fractal dimension was employed in this study to characterize the morphological characteristics of coarse aggregate particles including shape and angularity. Due to the limitations of the developed system, the surface texture was not evaluated in this research.

A unique method was presented in this paper for evaluating the morphological characteristic of the coarse aggregates and demonstrating their effects on the mechanical performance. Rutting, which normally occurs at high temperatures and under heavy loads, is common distress of asphalt pavement [12]. The high-temperature performance of asphalt pavement is primarily influenced by aggregate gradation, asphalt properties, climate conditions, traffic conditions, and aggregate characteristics [13]. While most previous studies focused on the first four factors, it is also worthy to investigate the effect of the coarse aggregate morphological characteristics on the high-temperature performance of asphalt mixtures. This paper aims to provide some useful information for highway engineers to improve and optimize the mixture 


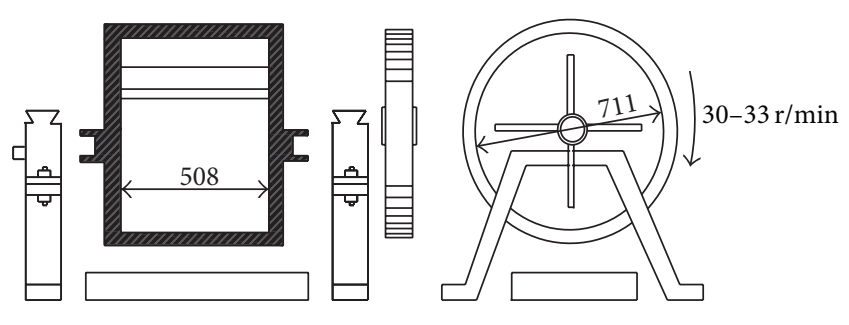

FIGURE 2: LA abrasion tester.

design by relating the macrostructure of aggregate to the actual performance of the pavement.

\section{Materials and Methods}

2.1. Aggregate Preparation. Andesite crushed aggregates were used in this study. The morphological characteristic of the aggregates was modified by the Los Angeles (LA) abrasion tester (Figure 2). The inner diameter and length of the LA abrasion tester's cylinder are $710 \pm 5 \mathrm{~mm}$ and $510 \pm$ $5 \mathrm{~mm}$, respectively (ASTM C 131-01). Four different particle sizes of aggregates $(16 / 19 \mathrm{~mm}, 13.2 / 16 \mathrm{~mm}, 9.5 / 13.2 \mathrm{~mm}$, and $4.75 / 9.5 \mathrm{~mm}$ ) obtained by sieving were washed and then dried in an oven at $105 \pm 5^{\circ} \mathrm{C}$ to a constant weight. Then, the dried aggregates were abraded for 200, 400, 600, 800, 1000 , and 1200 cycles, respectively, at $30-33 \mathrm{r} / \mathrm{min}$ by the LA abrasion tester without steel balls, as they may easily break the aggregates in the abrasion. The edges and corners of aggregates can be polished by the interaction between the aggregates, also between aggregates and the steel wall. Each sample was sieved again to remove the crumb of aggregates. Finally, along with aggregates without abrasion, there were 28 types of coarse aggregate samples $(4$ sizes $\times 7$ abrasion cycles) to prepare the asphalt mixtures, which were classified by different abrasion cycles and different aggregate sizes.

2.2. Measurement of Fractal Dimension. Several approaches have been developed to measure the fractal dimension of aggregate particles, like the slit island method, vertical section method, secondary electron curve method, and so forth [14]. In this study, the aggregate particles' fractal dimension was measured by the slit island method, which calculates the fractal dimension, $D$, by utilizing the perimeter, $P$, and the surrounding region's area, $A$, of the enclosed fractal curve, $C$. The aforementioned parameters are illustrated in Figure 3.

2.3. Determination of Fractal Dimension. According to dimensional analysis, for the Euclidean length of the fractal curve, $C$, the perimeter of the aggregate particle, $P_{E}$, can be expressed as

$$
P_{E}^{1 / D}=a_{0} \delta^{(1-D) / D} A^{1 / 2},
$$

where $\delta$ is the measured size, $a_{0}$ is a dimensionless constant called the shape factor, and $A$ is the area of the aggregate particle [15].

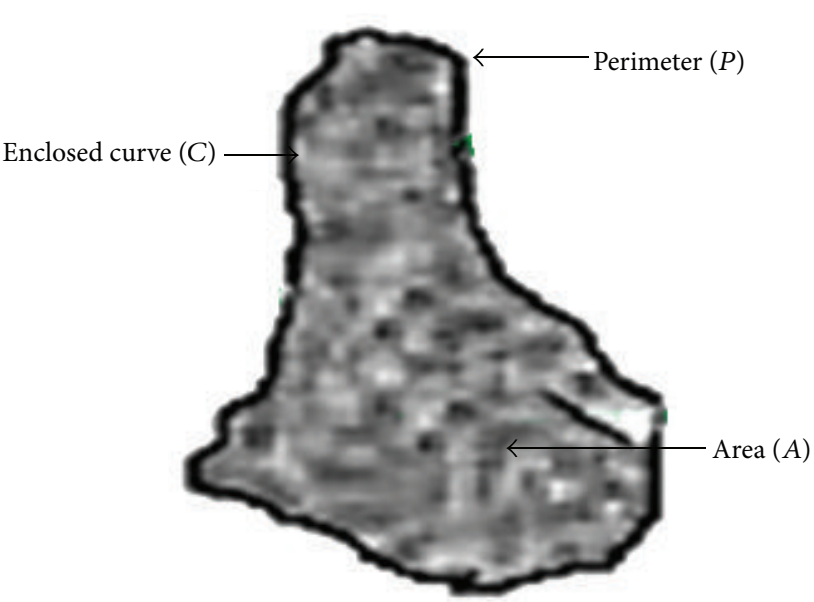

FIGURE 3: Illustration of the parameters for the slit island method.

The fractal dimension, $D$, can be expressed as

$$
D=\frac{\log \left(P_{E} / \delta\right)}{\left[\log a_{0}+\log \left(A^{1 / 2} / \delta\right)\right]} .
$$

The morphological image information of the coarse aggregate particles was obtained by a laboratory-developed Morphology Analysis System for Coarse Aggregates (MASCA), as shown in Figure 4. The symmetric illumination system was used in order to eliminate the occurrence of particle shadows in MASCA. A digital camera was installed above aggregates to obtain the information from the image. The calculated fractal dimension values are not dependent on the resolution of the imaging system if the digital camera can get a clear image of the shape and angularity of aggregates. In the MASCA system, the camera's highest resolution is $4272 * 2848$, and it has 12.2 million effective pixels; in addition, the EF $100 \mathrm{~mm} \mathrm{f} / 2.8$ prime lens was used. The geometric irregularity of coarse aggregates can be quantized by fractal dimension as the MASCA system can precisely obtain the shape and angularity. This system can be applied to easily measure the fractal dimension of $2.36 \mathrm{~mm}$ aggregate particles. The image was then transferred into the computer through a data cable. Based on the digital images obtained, $n$ perimeter values, $P_{E i}$, and $n$ area values, $A_{i}$, to various measuring sizes, and $\delta_{i}(i=1,2, \ldots, n)$ for each aggregate particle, the samples were then measured using the Image-Pro Plus software. Finally, the fractal dimension, $D$, was determined using linear regression between $\log \left(P_{E i} / \delta_{i}\right)$ and $\log \left(A_{i}{ }^{1 / 2} / \delta_{i}\right)$ as $D$ and $a_{0}$ are constants for a certain image with values ranging between 1 and 2 . The bigger the fractal dimension is, $D$, the more angular the aggregate is. The 140 aggregate particles of a certain size for different abrasion cycles were tested and were randomly taken from the corresponding stock pile. Three replicate tests were conducted to determine their variability. Table 1 presents the fractal dimensions of all the coarse aggregates used in the asphalt mixtures.

2.4. Mixture Materials. To evaluate the effects of the coarse aggregate morphological characteristics on the performance 


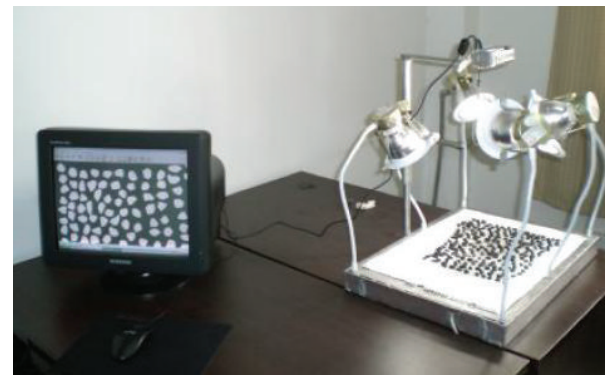

(a)

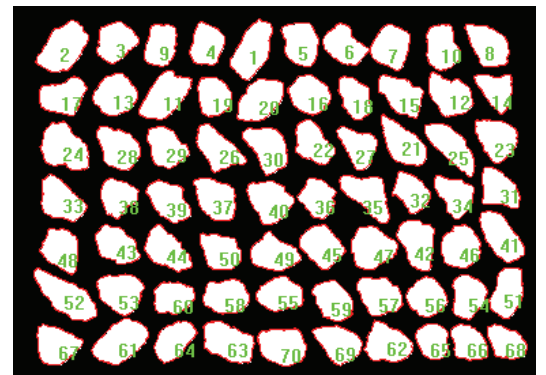

(b)

FIGURE 4: Illustration of fractal dimension measurement: (a) Morphology Analysis System for Coarse Aggregates (MASCA) and (b) boundary identification of aggregates.

TABLE 1: Average fractal dimension and coefficient of variation of aggregates with different abrasion cycles and different sizes.

\begin{tabular}{lcccc}
\hline \multirow{2}{*}{ Abrasion cycles } & \multicolumn{4}{c}{ Fractal dimension $D /$ coefficient of variation } \\
& $16 / 19 \mathrm{~mm}$ & $13.2 / 16 \mathrm{~mm}$ & $9.5 / 13.2 \mathrm{~mm}$ & $4.75 / 9.5 \mathrm{~mm}$ \\
\hline 0 & $1.0213 / 0.04$ & $1.0235 / 0.03$ & $1.0307 / 0.06$ & $1.0394 / 0.07$ \\
200 & $1.0191 / 0.02$ & $1.0202 / 0.02$ & $1.0284 / 0.08$ & $1.0375 / 0.02$ \\
400 & $1.0173 / 0.02$ & $1.0182 / 0.06$ & $1.0273 / 0.03$ & $1.0362 / 0.04$ \\
600 & $1.0161 / 0.05$ & $1.0168 / 0.05$ & $1.0262 / 0.03$ & $1.0343 / 0.03$ \\
800 & $1.0153 / 0.04$ & $1.0162 / 0.04$ & $1.0251 / 0.04$ & $1.0328 / 0.04$ \\
1000 & $1.0147 / 0.07$ & $1.0157 / 0.02$ & $1.0242 / 0.02$ & $1.0318 / 0.05$ \\
1200 & $1.0143 / 0.03$ & $1.0153 / 0.05$ & $1.0235 / 0.05$ & $1.0307 / 0.02$ \\
\hline
\end{tabular}

of various mixtures, three different aggregate gradations of asphalt mixture specimens, namely, dense-graded asphalt concrete (AC-16), gap-graded stone asphalt concrete (SAC16), and stone mastic asphalt (SMA-16), were fabricated to conduct the dynamic stability (DS) test and penetration shear test. SAC-16 is the skeleton dense-graded stone asphalt mixture which has a high percentage of coarse aggregate and a low void ratio. The gradation of each mixture type is shown in Figure 5. For all specimens, the effect of the coarse aggregate morphological characteristics on the performance of the asphalt mixture was investigated by altering abrasion cycles $(0,200,400,600,800,1000$, and 1200) on the coarse aggregate. Unprocessed fine aggregates were taken from the construction site from Shiyan City to Tianshui City to avoid interference of the fine aggregate morphological characteristics. A 90 penetration grade $\mathrm{SK}^{\mathrm{TM}}$ pure asphalt was used to prepare all of the mixtures. A lignin fiber with a density of $1.48 \mathrm{~g} / \mathrm{cm}^{3}$ was added to the SMA-16 mixture. The basic properties of the asphalt and aggregates used in the three mixtures are shown in Tables 2 and 3, respectively.

The optimum asphalt content, determined by the Marshall mixture design method, was $4.3 \%, 4.1 \%$, and $5.8 \%$ for AC-16, SAC-16, and SMA-16 mixtures, respectively. The same optimum asphalt content was used for the same grading mixture composed of the coarse aggregates with different numbers of abrasion cycles. The reason for using the same optimum asphalt content in the same grading mixture is to obtain the same asphalt film thickness [15] and to remove the influence of asphalt content on the rutting and penetration shear test results.
TABLE 2: Technical properties of the asphalt.

\begin{tabular}{lcc}
\hline Properties & Testing method & Tested value \\
\hline Specific gravity at $25^{\circ} \mathrm{C}\left(\mathrm{g} / \mathrm{cm}^{3}\right)$ & ASTM D 70 & 1.032 \\
Penetration at $25^{\circ} \mathrm{C}, 100 \mathrm{~g}(0.1 \mathrm{~mm})$ & ASTM D 5 & 83.5 \\
Penetration index $(\mathrm{PI})$ & ASTM D 5 & -1.29 \\
Softening point $\left({ }^{\circ} \mathrm{C}\right)$ & ASTM D 36 & 47.6 \\
$\begin{array}{l}\text { Ductility at } 25^{\circ} \mathrm{C}(\mathrm{cm}) \\
\text { Flash point }\left({ }^{\circ} \mathrm{C}\right)\end{array}$ & ASTM D 113 & $\geq 100$ \\
$\begin{array}{l}\text { Mass loss }\left(\mathrm{RTFO}, 85 \mathrm{~min}, \text { at } 163^{\circ} \mathrm{C}\right) \\
(\%)\end{array}$ & ASTM D 92 & 310 \\
\hline
\end{tabular}

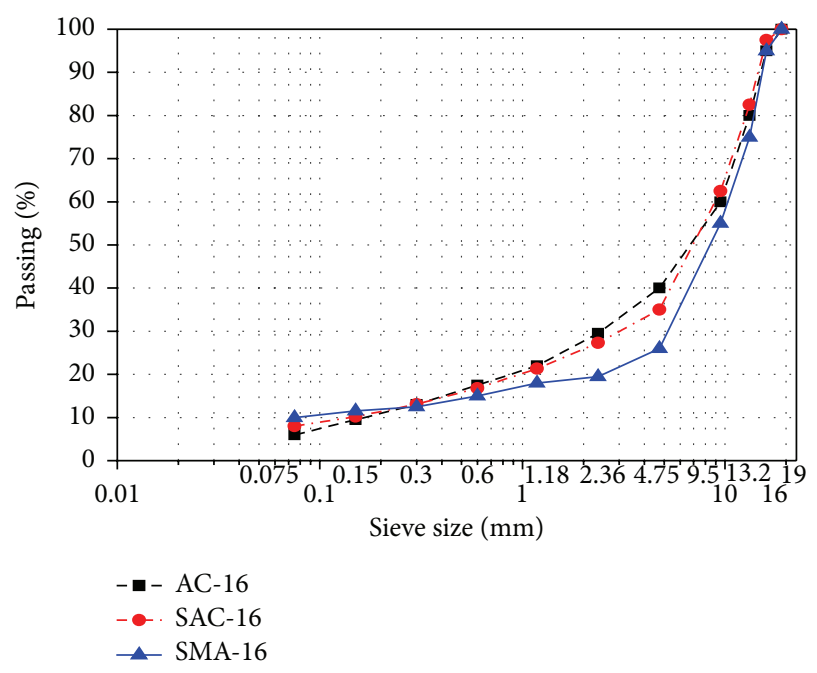

FIGURE 5: Gradation curves of three types of mixtures.

2.5. The Dynamic Stability Test and Penetration Shear Test. Both the dynamic stability (DS) test and the penetration shear test have been previously used to evaluate the hightemperature performance of asphalt mixtures. In order to understand the effects of the morphological characteristics of coarse aggregates on the high-temperature performance of asphalt mixtures, both tests were employed in this study. Based on the high-temperature performance test results, a relationship can be established between the coarse aggregate morphological characteristic and the high-temperature performance index of asphalt pavement. The dynamic stability (DS) test and penetration shear test were conducted on 
TABLE 3: Technical properties of coarse aggregates.

\begin{tabular}{lccc}
\hline Properties & Technical requirements & Tested value & Specification used \\
\hline Apparent specific gravity $\left(\mathrm{g} / \mathrm{cm}^{3}\right)$ & $>2.6$ & 2.746 & T0304-2005 \\
Crushing value \% & $<15$ & 12.54 & T0316-2005 \\
Abrasion value \% & $<26$ & 23.3 & T0317-2005 \\
Water absorption \% & $<2.0$ & 0.52 & T0304-2005 \\
Soundness \% & $\leq 12$ & 10.92 & T0314-2000 \\
\hline
\end{tabular}

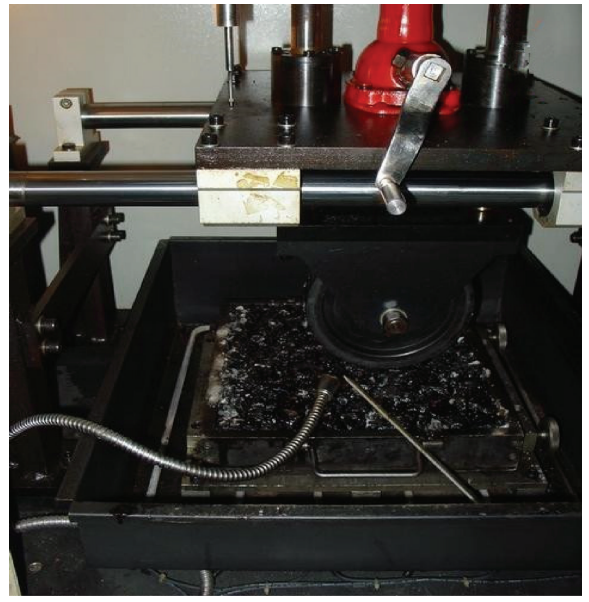

FIGURE 6: Internal part illustration for wheel rutting tester.

21 different mixtures comprised of different gradations and coarse aggregates subjected to different abrasion cycles. Tests were repeatedly conducted on three of the same specimens for each mixture. The DS test was conducted in accordance with Standard Test Methods (T0719-2011) of Bitumen and Bituminous Mixtures for Highway Engineering. Asphalt mixture slabs $(300 \mathrm{~mm} \times 300 \mathrm{~mm} \times 50 \mathrm{~mm})$ were prepared for the rutting test. The wheel of rutting tester is $200 \mathrm{~mm}$ (diameter) $\times 50 \mathrm{~mm}$ (wide). For the rutting tests, the temperature, applied load, and loading rate were set at $60^{\circ} \mathrm{C}$, $0.7 \mathrm{MPa}$, and $42 \mathrm{cycles} / \mathrm{min}$, respectively. The internal part of the wheel rutting tester is shown in Figure 6. The permanent deformation value, $d_{1}$, was recorded at 45 minutes of rolling, and then the second permanent deformation value, $d_{2}$, was recorded at 60 minutes of rolling. The dynamic stability was represented by the number of rolls while adding $1 \mathrm{~mm}$ of deformation [16]. The expression is shown as follows:

$$
\mathrm{DS}=\frac{630}{d_{2}-d_{1}}
$$

where DS is the dynamic stability.

The penetration shear test was conducted by the universal material testing device (MTS-810), as shown in Figure 7. The test's principle is that the circular steel head pressure was carried out on the specimen with a certain loading rate to simulate actual stress states of pavement structure. The maximum shear stress obtained by the penetration shear method can reflect the high-temperature shear performance of asphalt mixture. Before running the test, the specimens $(101 \mathrm{~mm}($ diameter $) \times 63.5 \mathrm{~mm}$ (height) $)$ were conditioned
TABLE 4: Basic parameters of shear strength of the $100 \mathrm{~mm} \times$ $63.5 \mathrm{~mm}$ specimen.

\begin{tabular}{lcccc}
\hline & Poisson's ratio & $\sigma_{1}$ & $\sigma_{2}$ & $\tau_{\max }$ \\
\hline Parameter value & 0.35 & 0.757 & 0.0686 & 0.344 \\
\hline
\end{tabular}

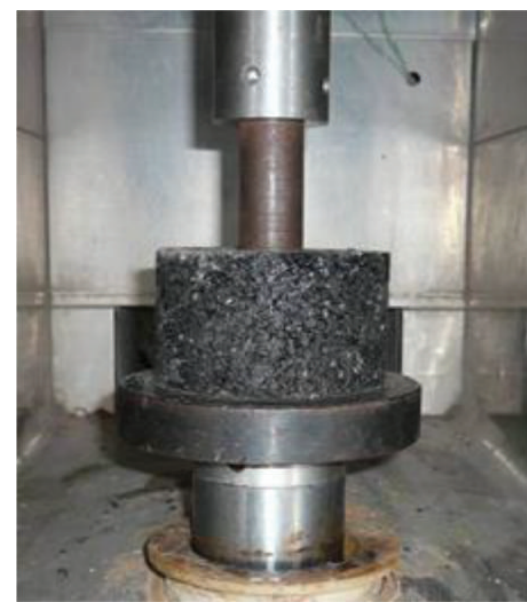

FIGURE 7: Penetration shear test device.

for 6 hours at a temperature of $60^{\circ} \mathrm{C}$. A load was applied with a rate of $1 \mathrm{~mm} / \mathrm{min}$. The penetration pressure head's size is set to $28.5 \mathrm{~mm}$ in order to simulate the actual stress condition in pavement. As basic parameters of shear strength, the main stress values at $1 \mathrm{MPa}$ head pressure were acquired by the three-dimensional finite element method [17]. The testing parameter values are summarized in Table 4 . Based on the parameters, the maximum shear stress was calculated considering the test penetration pressure. The relationship between the maximum shear stress and penetration pressure can be obtained as follows:

$$
S=\tau_{\max } P,
$$

where $S$ is the maximum shear stress and $P$ is the penetration pressure.

\section{Results and Discussions}

3.1. Results of Dynamic Stability Test and Penetration Shear Test. As shown in Figure 8, the dynamic stability, which is the high-temperature performance indicator, decreased with the increase in abrasion cycles, indicating that the morphological characteristic of coarse aggregates is an important factor 

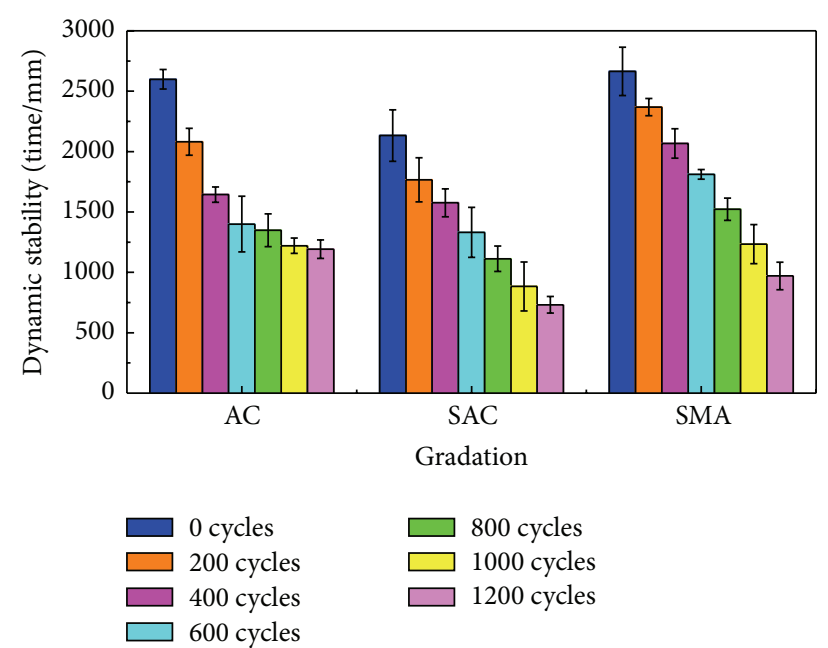

FIGURE 8: Rutting test results for AC-16, SMA-16, and SAC-16.

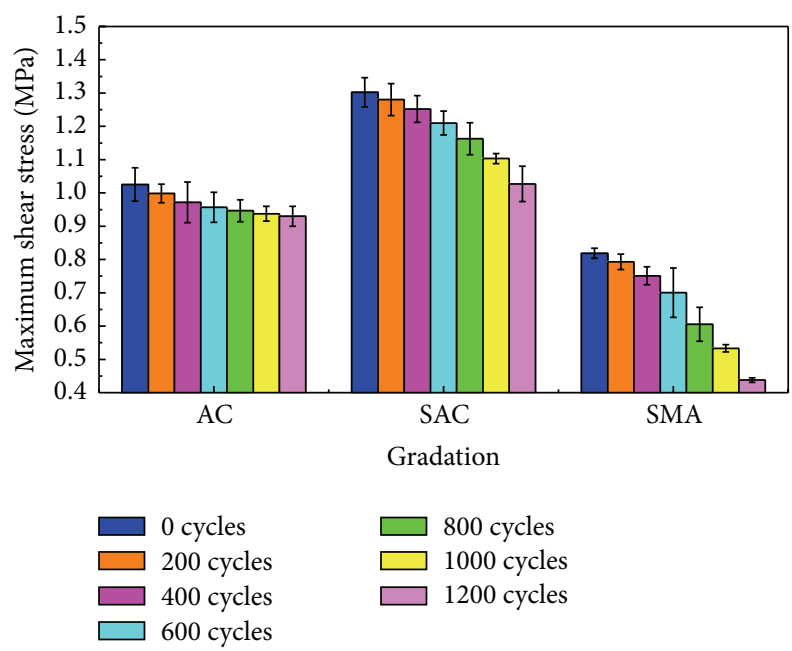

FIGURE 9: Maximum penetration shear test results for AC-16, SMA16 , and SAC-16.

that affects the high-temperature performance. Similarly, Figure 9 shows that the maximum shear stress decreased with the increase in abrasion cycles. Shape and angularity create greater interlock between particles; in addition, texture develops a strong friction surface among the coarse aggregates, resulting in better stability and shear resistance of the mixture [18]. The dynamic stability and maximum shear stress of the AC-16 mixture significantly decreased when the abrasion cycles changed from 0 to 600 , but this seems not to be significant when the abrasion time changed from 600 to 1200 . Unlike the AC-16 mixture, the dynamic stability and maximum shear stress for the SAC-16 and SMA16 mixtures decreased continuously when the abrasion time changed from 0 to 1200 .

This is because the morphological characteristic of coarse aggregate became weaker as abrasion times increase. In addition, it can be concluded that the influence of the morphological characteristic of coarse aggregates on the rutting resistance of the AC- 16 asphalt mixture was very
TABLE 5: Correlation analysis results between fractal dimension of coarse aggregates and high-temperature stability of asphalt mixtures.

\begin{tabular}{lcccc}
\hline \multirow{2}{*}{ Mixture type } & \multicolumn{4}{c}{ Correlation coefficient $(r)$} \\
& $16 / 19 \mathrm{~mm}$ & $13.2 / 16 \mathrm{~mm}$ & $9.5 / 13.2 \mathrm{~mm}$ & $4.75 / 9.5 \mathrm{~mm}$ \\
\hline AC-16 & 0.988 & 0.990 & 0.970 & 0.959 \\
SAC-16 & 0.982 & 0.965 & 0.992 & 0.995 \\
SMA-16 & 0.964 & 0.941 & 0.985 & 0.988 \\
\hline
\end{tabular}

TABLE 6: Correlation analysis results between fractal dimension of coarse aggregates and maximum shear stress of asphalt mixtures.

\begin{tabular}{lcccc}
\hline \multirow{2}{*}{ Mixture type } & \multicolumn{4}{c}{ Correlation coefficient $(r)$} \\
& $16 / 19 \mathrm{~mm}$ & $13.2 / 16 \mathrm{~mm}$ & $9.5 / 13.2 \mathrm{~mm}$ & $4.75 / 9.5 \mathrm{~mm}$ \\
\hline AC-16 & 0.975 & 0.977 & 0.968 & 0.962 \\
SAC-16 & 0.889 & 0.852 & 0.896 & 0.901 \\
SMA-16 & 0.881 & 0.842 & 0.903 & 0.908 \\
\hline
\end{tabular}

limited when abrasion cycle is above a certain extent, as the AC-16 asphalt mixture has a small percentage of coarse aggregates, and its antideformation performance at high temperature is contributed by both the coarse aggregate and the asphalt mastic (asphalt and fine aggregates). However, the gap-graded mixture (SAC-16, SMA-16) mainly relies on interlocked skeleton structure formed by coarse aggregate to bear vehicle loading, so that the rutting resistance of SAC-16 and SMA-16 mixtures kept reducing with the increase of the abrasion cycle.

3.2. Correlation between Fractal Dimension of Coarse Aggregate Particles and High-Temperature Performance Index. Considering the effect of different particle sizes of coarse aggregates on mixture performance, partial correlation analysis was applied by the Statistical Product and Service Solutions (SPSS) software, which provides the functions of data management, statistical analysis, chart analysis, and output management. Partial correlation analysis can eliminate the effect of different particle sizes so that it can analyze the linear correlation between different abrasion cycles and the high-temperature performance index of asphalt mixtures independently. Tables 4 and 5 show the correlation between the fractal dimension of coarse aggregate particles with different particle sizes and abrasion cycles and the hightemperature performance index of the asphalt mixtures with different gradations.

As presented in Tables 5 and 6, the fractal dimension of coarse aggregate particles correlates well with the dynamic stability and maximum shear stress indexes for AC, SAC, and SMA mixtures. Partial correlation analysis results show that the fractal dimension is a good index to quantitatively characterize coarse aggregates geometric morphology, including shape and angularity. The fractal dimension can help to improve the high-temperature performance of asphalt pavement in terms of coarse aggregate shape. The fractal dimensions of different sizes of aggregates may have various effects on the high-temperature performance (in regard to high-temperature stability and maximum shear stress). For the $\mathrm{AC}-16$, the fractal dimension of the coarse aggregates 


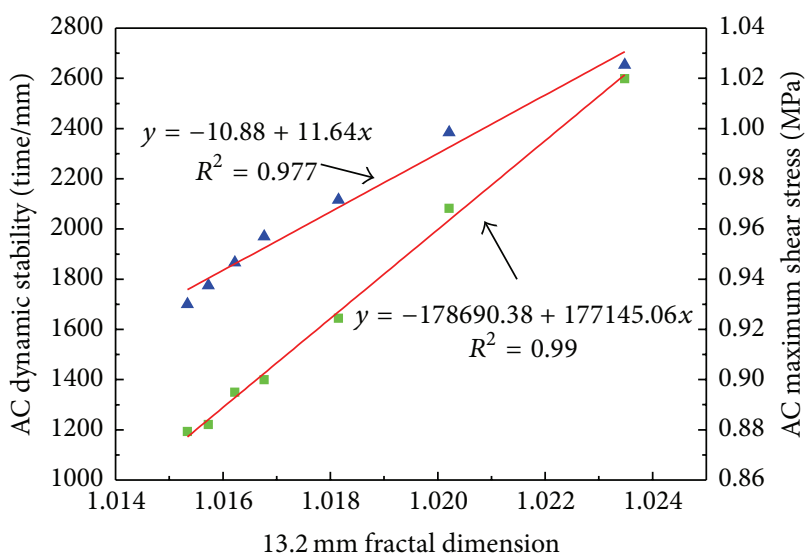

- Linear fit of dynamic stability

- Linear fit of maximum shear stress

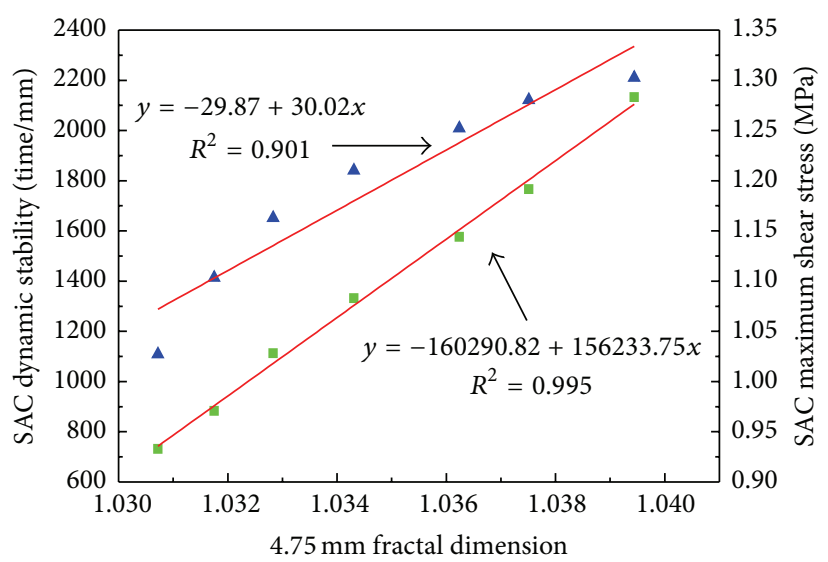

- Linear fit of dynamic stability

- Linear fit of maximum shear stress

(b)

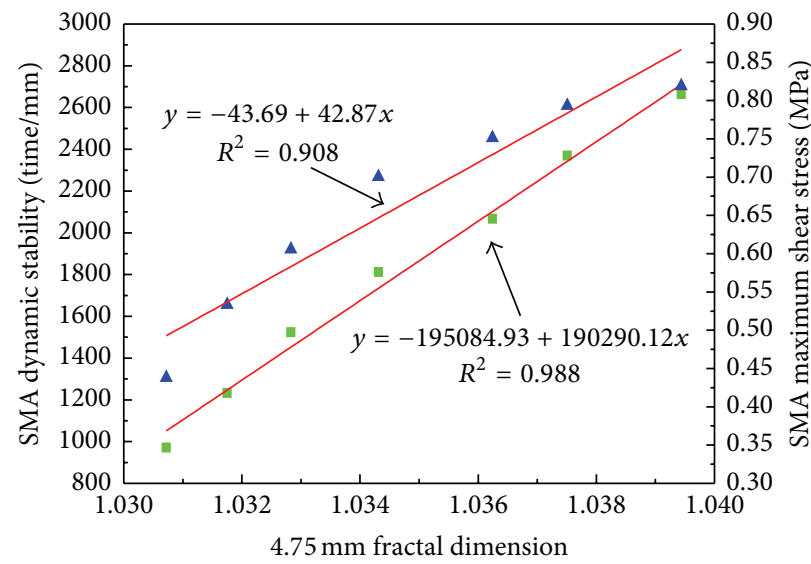

- Linear fit of dynamic stability

- Linear fit of maximum shear stress

(c)

FIgURE 10: Regression analysis results: (a) AC-16, (b) SAC-16, and (c) SMA-16.

with the size of 13.2/16 $\mathrm{mm}$ has the strongest correlation with the high-temperature performance compared to aggregates of other sizes. For the SAC-16 and SMA-16, the most influential aggregate size is $4.75 / 9.5 \mathrm{~mm}$.

\subsection{Analysis of Regression between Fractal Dimension of} Coarse Aggregate Particles and High-Temperature Performance Index of Asphalt Mixtures. To further analyze the relationship between the fractal dimension of coarse aggregate particles and high-temperature performance of asphalt mixtures, SPSS software was used to make linear regression to fit the relation between the fractal dimension of coarse aggregate particles with the best correlation and the hightemperature performance index for the three types of asphalt mixtures. The regression results are shown in Figure 10.

Figure 10 shows that the fractal dimension of coarse aggregate particles with the best correlation has a strong correlation with the dynamic stability index for the AC, SAC, and SMA asphalt mixtures. The dynamic stability of the asphalt mixture decreased with the decrease in fractal dimension of coarse aggregate particles. In addition, the correlation between the fractal dimension of coarse aggregate particles with the best correlation and maximum shear stress index is also good for the AC, SAC, and SMA asphalt mixtures. The maximum shear stress of asphalt mixture decreases with the decrease in the fractal dimension of coarse aggregate particles. Because of the decrease in coarse aggregate angularity, the interlocking of asphalt mixture was weakened, causing a drop in the shear resistance of the asphalt mixture. As trend line in the penetration shear test results is consistent with that of the rutting test results for all mixtures, the penetration shear test is also a valid method to evaluate the high-temperature performance of asphalt mixtures. The fractal dimension of coarse aggregate particles is a useful index to quantify the aggregate morphology characteristics (shape, angularity). To regulate the quality of aggregates effectively and reliably, the fractal dimension values of coarse aggregates are recommended to provide a basis for the properties of asphalt mixtures in terms of the morphological characteristics of the aggregate. 


\section{Conclusions}

The fractal dimension was proposed to characterize the morphological characteristics of coarse aggregate through the application of the fractal geometry method. The main objective of this study was to study the influence of the morphological characteristics of the coarse aggregates on the high-temperature performance of the asphalt mixture. To achieve this objective, the dynamic stability test and penetration shear tests were employed for the purpose of high-temperature performance evaluation.

The dynamic stability and penetration shear test results indicate that higher angularity of coarse aggregates leads to stronger permanent deformation resistance for all three types of asphalt mixtures. However, the effect of the morphological characteristic of coarse aggregates on the performance of the dense-graded asphalt mixture is inconspicuous when it changes to a certain extent. Compared with the densegraded asphalt mixture, the morphological characteristic of coarse aggregates affects the performance of gap-graded mixtures more strongly due to the higher percentage of coarse aggregates $(>70 \%)$.

The fractal dimension of coarse aggregate particles retained on the $13.2 \mathrm{~mm}$ control sieve correlates best with high-temperature performances for the AC-16 mixture, followed by those retained on $16 \mathrm{~mm}, 9.5 \mathrm{~mm}$, and $4.75 \mathrm{~mm}$ sieve, respectively. For the SAC-16 and SMA-16 mixtures, the fractal dimension of coarse aggregate particles retained on the $4.75 \mathrm{~mm}$ control sieve correlates best with hightemperature performances, followed by those retained on $9.5 \mathrm{~mm}, 16 \mathrm{~mm}$, and $13.2 \mathrm{~mm}$ sieve, respectively.

Good linear correlations were observed between the fractal dimension and the high-temperature performance indexes (the dynamic stability and maximum shear stress from the DS test and the penetration shear test, resp.).

It is recommended that the impact of the morphological characteristic of coarse aggregates on the other properties of asphalt mixture be investigated. Furthermore, a similar approach may be applied to analyze the morphological characteristic of fine aggregates. Coarse aggregate characteristics with fractal dimension as a quantified index should be combined with aggregate gradation, asphalt binder property, and air voids to estimate the performance of asphalt pavement. In addition, it is recommended that the threedimensional morphological characteristic of aggregates be investigated using nondestructive testing equipment, such as $\mathrm{X}$-ray computer tomography.

\section{Conflict of Interests}

The authors declare that there is no conflict of interests regarding the publication of this paper.

\section{Acknowledgments}

This research is supported by the research project of the Ministry of Science and Technology of China (2014BAG05B04), the National Natural Science Foundation of China (NSFC) (no. 51378074), the Fundamental and Applied Research
Project of the Chinese National Transportation Department (2014 319812 180), and the Special Fund for Basic Scientific Research of Central Colleges, Changan University (CHD310821153503).

\section{References}

[1] Y. Liu, Z. You, Q. Dai, and J. Mills-Beale, "Review of advances in understanding impacts of mix composition characteristics on asphalt concrete (AC) mechanics," International Journal of Pavement Engineering, vol. 12, no. 4, pp. 385-405, 2011.

[2] M. Tokyay and T. Akcaoglu, "Determining aggregate size \& shape effect on concrete microcracking under compression by means of a degree of reversibility method," in Proceedings of the 11th International Conference on Fracture (ICF11 '05), vol. 2, pp. 1357-1362, Turin, Italy, March 2005.

[3] AASHTO, Standard Specifications for Transportation Materials and Methods of Sampling and Testing, T304, AASHTO Bookstore, 2015.

[4] I. Ishai and H. Gellber, "Effect of geometric irregularity of aggregates on the properties and behavior of asphalt concrete," Journal of Association of Asphalt Paving Technologists, vol. 51, pp. 494-521, 1982.

[5] C. Chandan, K. Sivakumar, T. Fletcher, and E. Masad, "Application of imaging techniques to geometry analysis of aggregate particles," Journal of Computing in Civil Engineering, vol. 18, no. 1, pp. 75-82, 2004.

[6] C. Browne, F. A. Rauch, T. C. Haas, and H. Kim, "Comparison tests of automated equipment for analyzing aggregate gradation," in Proceedings of the 9th Annual Symposium of the International Center for Aggregates Research (ICAR '11), Austin, Tex, USA, 2011.

[7] C. Rao, E. Tutumluer, and I. T. Kim, "Quantification of coarse aggregate angularity based on image analysis," Transportation Research Record, no. 1787, pp. 117-124, 2002.

[8] E. Masad, "The development of a computer controlled image analysis system for measuring aggregate shape properties," National Cooperative Highway Research Program NCHRPIDEA Project 77 Final Report, Transportation Research Board, National Research Council, 2003.

[9] L. Wang, W. Sun, E. M. Lally, and A. Wang, "Application of LADAR in the analysis of aggregate characteristics," National Cooperative Highway Research Program Report 724, Transportation Research Board, National Research Council, 2012.

[10] W. D. Fei, W. G. Chu, and D. Z. Yang, "Fractal characteristic of the microstructure in Alnico8," Journal of Materials Science Letters, vol. 19, no. 14, pp. 1221-1223, 2000.

[11] A. G. Kokkalis, G. H. Tsohos, and O. K. Panagouli, "Consideration of fractals potential in pavement skid resistance evaluation," Journal of Transportation Engineering, vol. 128, no. 6, pp. 591-595, 2002.

[12] H. Wang, Y. Bu, D. Wang, and M. Oeser, "3D characterisation of the grain sphericity and angularity with the aid of computed tomography," Bauingenieur, vol. 90, pp. 436-443, 2015.

[13] J. Zhang, Z. Fan, K. Fang, J. Pei, and L. Xu, "Development and validation of nonlinear viscoelastic damage (NLVED) model for three-stage permanent deformation of asphalt concrete," Construction and Building Materials, vol. 102, no. 1, pp. 384-392, 2016.

[14] K. Sasajima and T. Tsukada, "Measurement of fractal dimension from surface asperity profile," International Journal of Machine Tools and Manufacture, vol. 32, no. 1-2, pp. 125-127, 1992. 
[15] A. Topal and B. Sengoz, "Determination of fine aggregate angularity in relation with the resistance to rutting of hot-mix asphalt," Construction and Building Materials, vol. 19, no. 2, pp. 155-163, 2005.

[16] X. Ji, N. Zheng, Y. Hou, and S. Niu, "Application of asphalt mixture shear strength to evaluate pavement rutting with accelerated loading facility (ALF)," Construction and Building Materials, vol. 41, pp. 1-8, 2013.

[17] Y.-F. Bi and L.-J. Sun, "Research on test method of asphalt mixture's shearing properties," Journal of Tongji University, vol. 33, no. 8, pp. 1036-1040, 2005 (Chinese).

[18] J. E. Stephens and K. C. Sinha, "Effect of aggregate shape on bituminous mix characteristic," Association of Asphalt Paving Technologists, vol. 47, pp. 434-456, 1978. 

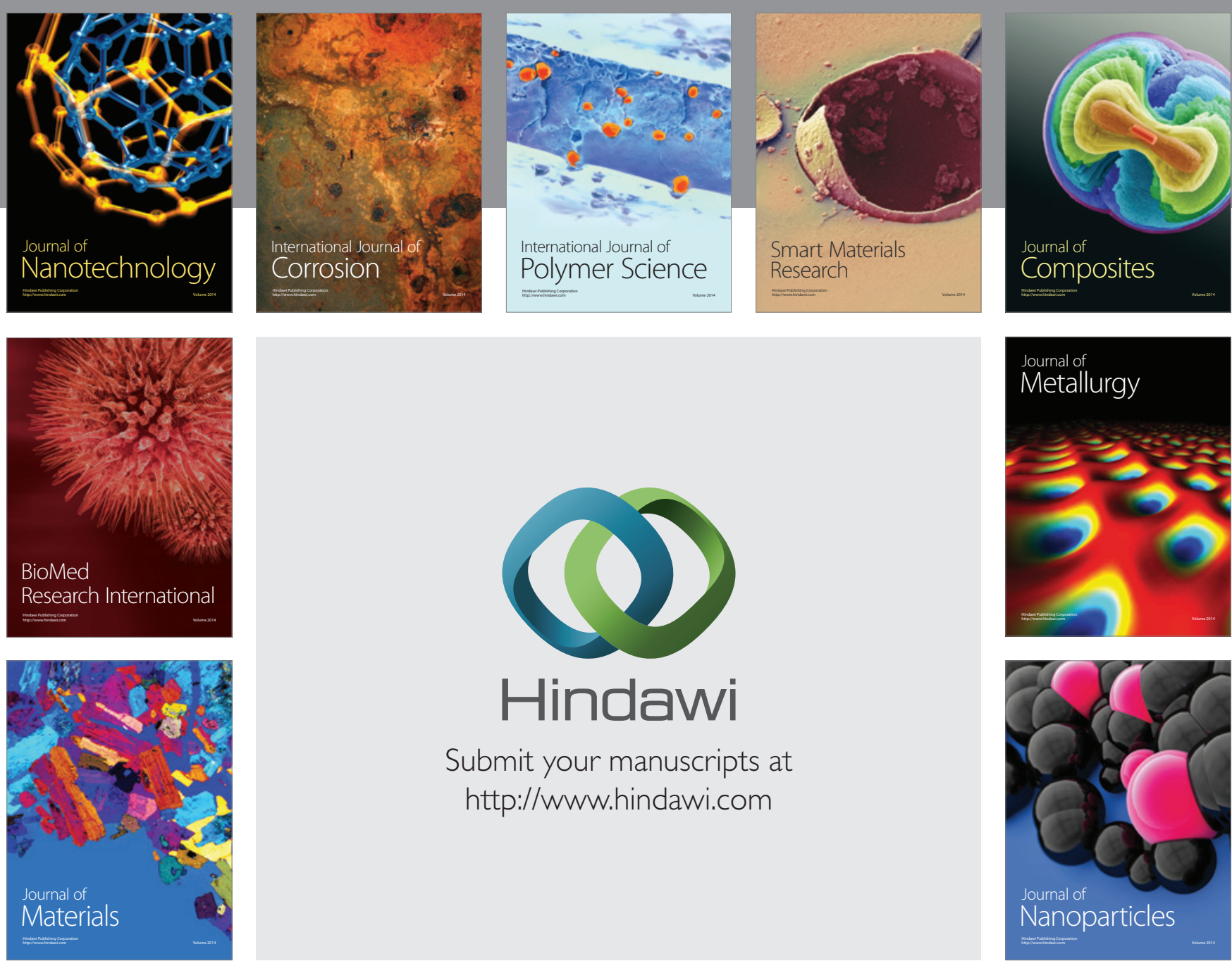

\section{Hindawi}

Submit your manuscripts at

http://www.hindawi.com

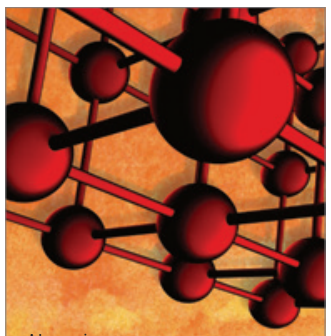

Materials Science and Engineering
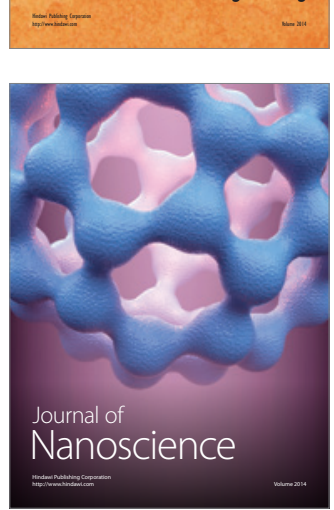
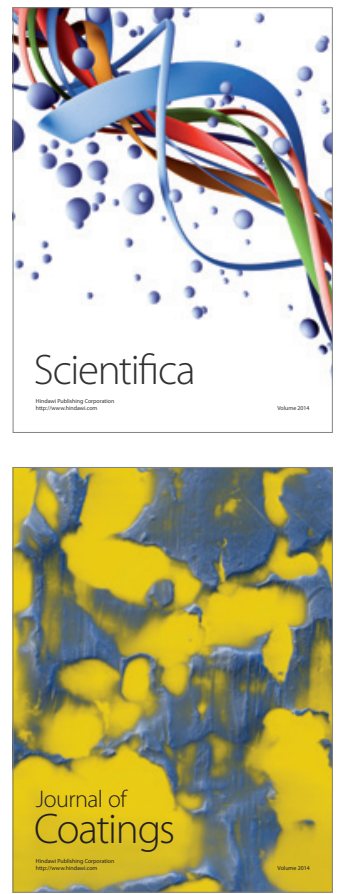
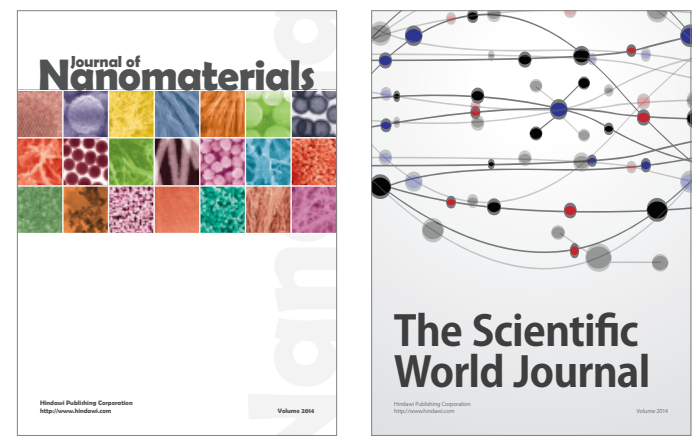

The Scientific World Journal
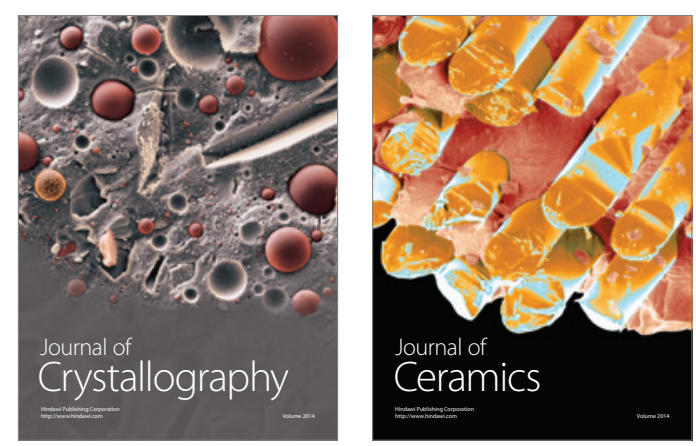
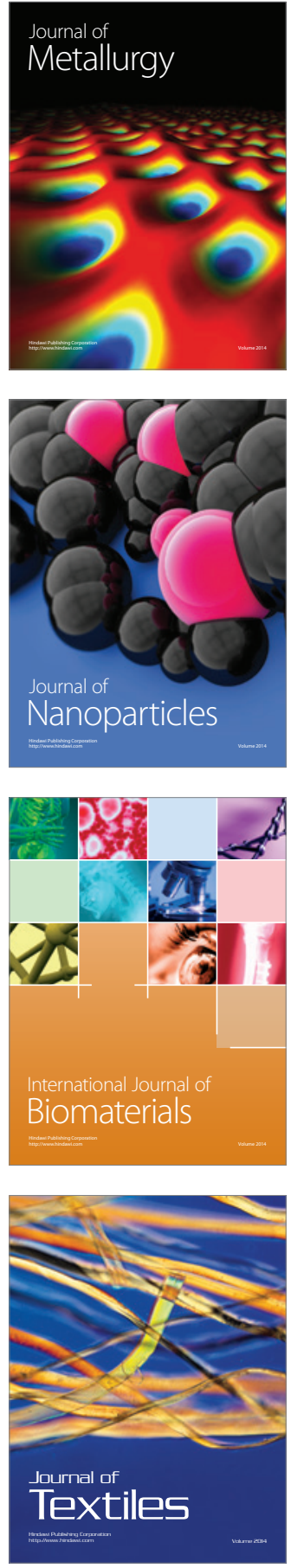